\title{
Symbiosis of sea anemones and hermit crabs: different resource utilization patterns in the Aegean Sea
}

\author{
Anna-Maria Vafeiadou • Chryssanthi Antoniadou • \\ Chariton Chintiroglou
}

Received: 11 January 2010/Revised: 26 September 2011/Accepted: 29 September 2011/Published online: 19 October 2011 (C) Springer-Verlag and AWI 2011

\begin{abstract}
The small-scale distribution and resource utilization patterns of hermit crabs living in symbiosis with sea anemones were investigated in the Aegean Sea. Four hermit crab species, occupying shells of nine gastropod species, were found in symbiosis with the sea anemone Calliactis parasitica. Shell resource utilization patterns varied among hermit crabs, with Dardanus species utilizing a wide variety of shells. The size structure of hermit crab populations also affected shell resource utilization, with small-sized individuals inhabiting a larger variety of shells. Sea anemone utilization patterns varied both among hermit crab species and among residence shells, with larger crabs and shells hosting an increased abundance and biomass of $C$. parasitica. The examined biometric relationships suggested that small-sized crabs carry, proportionally to their weight, heavier shells and increased anemone biomass than larger ones. Exceptions to the above patterns are related either to local resource availability or to other environmental factors.
\end{abstract}

Keywords Symbiosis - Mutualism - Distribution · Biometry · Aegean Sea

Communicated by Martin Thiel.

Electronic supplementary material The online version of this article (doi:10.1007/s10152-011-0279-7) contains supplementary material, which is available to authorized users.

A.-M. Vafeiadou · C. Antoniadou $(\bowtie) \cdot C$. Chintiroglou Department of Zoology, School of Biology, Aristotle University, 54141 Thessaloniki, Greece

e-mail: antonch@bio.auth.gr

\section{Introduction}

Living organisms have complex interrelations, which, when referring to close associations between two species, are defined using the generic term symbiosis (Henry 1966). One of the most common cases of symbiosis in marine ecosystems is between cnidarians and hermit crabs (Decapoda: Anomura); over 100 species of cnidarians have been reported in such associations (Williams and McDermott 2004). Sea anemones (Anthozoa: Actiniaria), though, are the only cnidarian symbionts that are actively hosted by hermit crabs and not haphazardly fixed on their gastropod shells during larval settlement (Gusmão and Daly 2010). The development of this symbiosis depends strongly on the availability of gastropod shells, which provide both refuge for hermit crabs and substratum for the settlement of sea anemones (Conover 1978; Brooks 1989).

These associations in most cases constitute impressive examples of facultative mutualism, since the symbiosis is reciprocally advantageous for both partners (Brooks and Gwaltney 1993; Patzner 2004), and not exclusively obligatory (Hazlett 1981). Through the symbiosis both partners gain protection against predators, the hermit crab via the anemone's nematocysts (Brooks 1989) and the sea anemone via the hermit crab's behavior of avoiding or even fighting animals attempting to prey on their attached sea anemones (Brooks and Gwaltney 1993). The sea anemone gains additional benefits by consuming residues from the hermit crab's food, and by exploring additional resources via its movement as it increases its dispersal capability and gains suitable substratum (Brooks 1989; Gusmão and Daly 2010). The great importance of the symbiosis is manifested by the behavior of the hermit crabs. Under increased levels of predation, they inhabit shells with more sea anemones (Ross and Boletzky 1979), transferring the anemones when 
changing a shell, or they even steal sea anemones from other crabs (Ross 1979). However, when being starved, hermit crabs may prey on the anemones attached on their shell (Imafuku et al. 2000).

In spite of the intensive efforts to cover this scientific field, the symbiosis of sea anemones with hermit crabs is not yet fully understood. The available information refers mainly to the diversity of the associated epibiotic organisms (Stachowitsch 1980; Williams and McDermott 2004), and to the behavioral patterns of hermit crabs with respect to sea anemones and shell resource exploitation. A number of studies manifest different shell resource utilization patterns according to size and shell availability (Hazlett 1995; Wada et al. 1997) taking into account the energetic constraints of carrying a shell (Hahn 1998). Intrinsic shell properties (e.g., shape, weight, spines, center of gravity, and shell axis) are other important factors in shell selection by hermit crabs (Reese 1963; Caruso and Chemello 2009), influencing also the placement of sea anemones on the shell (Ross and Boletzky 1979; Brooks 1989). The previous experience in shell selection (Hazlett 1995; Hahn 1998; Gherardi 2006) and the preference of some hermit crabs toward shells of specific gastropod species (Reese 1963; Borjesson and Szelistowski 1989) have been also discussed.

Certain morphological characteristics of both sea anemones and hermit crabs also seem to directly affect the symbiosis, but the available data do not conform to a general common pattern among species. For example, a trend for small, young crabs to utilize larger shells in proportion to their body size has been proposed (Balasch and Cuadras 1976; Chintiroglou et al. 1992), while another study reports that large, old crabs utilize larger and heavier shells (Caruso and Chemello 2009). Considering sea anemone utilization, very few data exist. A single relevant study has been performed suggesting that hermit crabs prefer small-sized anemones (Christidis et al. 1997). However, this study included a local population of a single hermit crab species; thus, generalization of such patterns cannot be done.

Considering all the above, the main goal of the present study was to examine the symbiosis of sea anemones with hermit crabs ( $\mathrm{Hc} / \mathrm{Sa}$ symbiosis) in the wider area of the Aegean Sea. This was accomplished by providing comprehensive data on the diversity, distribution, and biometry of the involved species. Emphasis was given on shell resource and sea anemone utilization patterns, considering the different hermit crab species involved, and/or the different species of gastropod shells inhabited by the hermit crabs.

\section{Materials and methods}

Sampling was carried out at Thermaikos Gulf $(2005,2006$, 2007, and 2008), in the northern Aegean Sea, and at
Spetses (2007 and 2008), Mykonos (2005 and 2006), and Crete (2006 and 2007) islands, in the southern Aegean Sea (Fig. 1). Eight randomly selected stations were located in the northern Aegean Sea, in which the sea bottom consists of maerl beds (T1 $35 \mathrm{~m}$ depth), seagrass meadows (T2 $40 \mathrm{~m}$, T3 $20 \mathrm{~m}, \mathrm{~T} 420 \mathrm{~m}$, and T6 $40 \mathrm{~m}$ ), or mud (T5 $55 \mathrm{~m}$, T7 40-60 m, and T8 75-95 m). Nine randomly selected stations were located in the southern Aegean Sea, where the substratum was either soft, i.e., sandy with seagrass meadows (M2 $25 \mathrm{~m}, \mathrm{M} 325 \mathrm{~m}, \mathrm{C} 320 \mathrm{~m}$ ), or consisted of rocks and maerl beds (S1 $20 \mathrm{~m}, \mathrm{M} 135 \mathrm{~m}, \mathrm{M} 425 \mathrm{~m}, \mathrm{C} 1$ $30 \mathrm{~m}, \mathrm{C} 220 \mathrm{~m}$, and C4 $35 \mathrm{~m}$ ).

Samples, i.e., hermit crabs (with and without sea anemones), were collected using trammel nets (five replicates using bottom nets trawled over a distance of $3 \mathrm{~km}$, mesh size: $20 \mathrm{~mm}$ ) and bottom trawling (one haul lasting $4 \mathrm{~h}$ and covering a distance of $15 \mathrm{~km}$, mesh size: $20 \mathrm{~mm}$ ). The latter method was used only at two stations in Thermaikos Gulf (T7, T8). The collected samples were stored separately in $9 \%$ formaldehyde.

In the laboratory, each sample was identified to species level, and the percentage of each hermit crab species that hosted sea anemones to the total number of the hermit crabs of this species was assessed. The weight of hermit crabs, gastropod shells, and sea anemones was estimated, as formalin wet weight, with an electronic scale to the nearest $\mathrm{mg}$, only for those hermit crabs that hosted sea anemones $(\mathrm{Hc} / \mathrm{Sa}$ symbiosis). To describe the types of $\mathrm{Hc} / \mathrm{Sa}$ symbiosis, the following parameters were calculated: (1) number of hermit crab individuals in symbiosis with sea anemones, (2) diversity of shell utilization, estimated as the number of different gastropod shells utilized by each hermit crab species, and (3) number of hermit crab species utilizing a specific gastropod shell. Multivariate analyses were used to compare the spatial distribution of $\mathrm{Hc} / \mathrm{Sa}$ symbiosis types. Non-metric multidimensional scaling ordination (nMDS) via Bray-Curtis distances was used to visualize changes in the composition of the $\mathrm{Hc} / \mathrm{Sa}$ symbiosis across sampling sites, taking also into account the diversity of gastropod shell fauna. Analysis of similarity (ANOSIM) was used to test for differences in composition of the $\mathrm{Hc} / \mathrm{Sa}$ symbiosis between the various types of substratum (i.e., meadows, maerl beds, rocky, and muddy bottoms). Since only seagrass meadows were equally sampled in the northern and southern Aegean Sea, these data were used to compare the distribution of $\mathrm{Hc} / \mathrm{Sa}$ symbiosis types between the two geographic sectors. Multivariate analyses were performed using the Primer package (Clarke and Gorley 2006).

The population structure of each hermit crab species that hosted sea anemones was analyzed by constructing sizefrequency distributions based on the weight of hermit crabs. These data were used to assess shell utilization of each hermit crab species in relation to its size. 
Fig. 1 Map of the study area indicating sampling stations

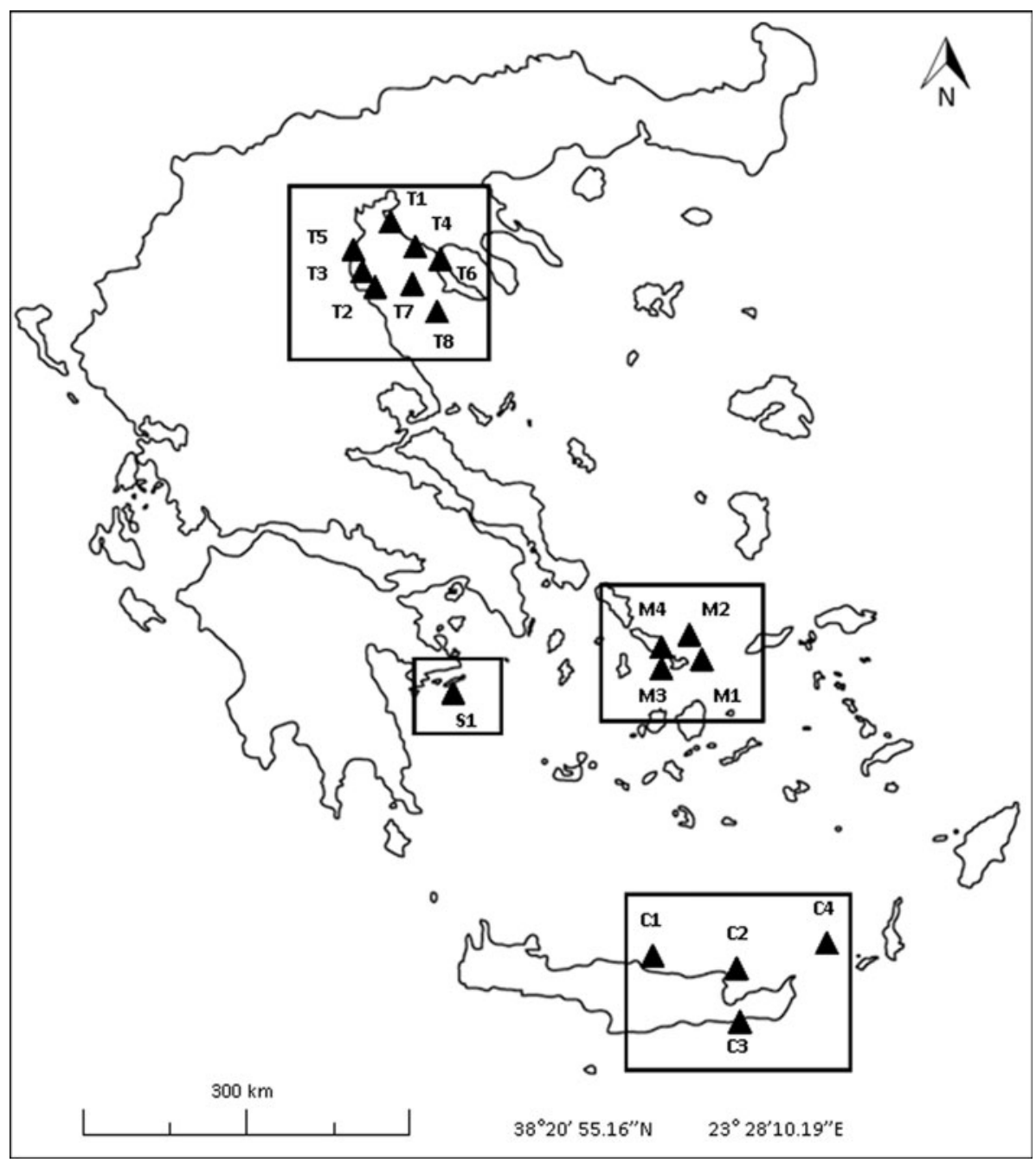

Multivariate general linear model analysis of variance (MANOVA) was used to test for differences in the abundance and the biomass of sea anemones associated with hermit crabs according to hermit crab and gastropod species (two-factor unbalanced design). The Bonferroni test was used for post hoc comparisons. MANOVAs were performed using the SPSS software package.

To examine the biometric relationships of the participant species in the $\mathrm{Hc} / \mathrm{Sa}$ symbiosis, the relationships between the hermit crab weight and (1) the weight of the residence shell, which describes the crab's ability to carry its shell, and (2) the total weight of the hosted sea anemones, which describes the crab's ability to collect and carry sea anemones, were estimated separately for each hermit crab species found, applying linear regression analysis using the power model, i.e., $y=a x^{b}$ (Sokal and Rohlf 1987), where $x=$ hermit crab weight. A $t$ test with a confidence level of $95 \%$ was applied to detect whether these relationships followed isometry $(b=1)$ or allometry.

\section{Results}

A total of 546 hermit crabs were collected and identified as belonging to eight species. Among these, only 193 individuals $(35.34 \%)$, belonging to four hermit crab species, namely Paguristes eremita, Dardanus arrosor, D. calidus, and Pagurus excavatus, carried sea anemones, all belonging to the species Calliactis parasitica. The 313 remaining individuals $(57.33 \%)$ of the aforementioned species and the 40 individuals $(7.33 \%)$ of the species Clibanarius erythropus, Pagurus cuanensis, P. anachoretus, and Calcinus tubularis were not associated with sea anemones. Thus, four types of $\mathrm{Hc} / \mathrm{Sa}$ symbiosis were detected, utilizing the shells of nine gastropod species (Table 1). The species Paguristes eremita and Pagurus excavatus were mainly recorded in Thermaikos samples, while Dardanus species were most frequently found in samples from the southern Aegean Sea. The associations of the hermit crabs Paguristes eremita and Dardanus calidus with Calliactis 
Table 1 Diversity and distribution of the Hc/Sa symbiosis types

\begin{tabular}{|c|c|c|c|c|c|c|c|c|}
\hline \multicolumn{3}{|l|}{$\mathrm{Hc} / \mathrm{Sa}$ symbiosis types } & \multicolumn{2}{|l|}{ Shell utilization } & \multicolumn{4}{|l|}{ Distribution } \\
\hline Anemones with hermit crabs & $P \%$ & $N$ & & Ns & Thermaikos & Spetses & Mykonos & Crete \\
\hline Calliactis parasitica (Cough, 1842) & 27.5 & 75 & Ds $=3$ & & & & & \\
\hline \multirow[t]{3}{*}{ Paguristes eremita (Linnaeus, 1767) } & & & Hexaplex trunculus (Linnaeus, 1758) & 46 & $X$ & & & \\
\hline & & & Bolinus brandaris (Linnaeus, 1758) & 28 & $\mathrm{X}$ & & & \\
\hline & & & Bolma rugosa (Linnaeus, 1767) & 1 & & & $X$ & \\
\hline Calliactis parasitica (Cough, 1842) & 60.9 & 39 & Ds $=3$ & & & & & \\
\hline \multirow[t]{3}{*}{ Pagurus excavatus (Herbst, 1791) } & & & Bolinus brandaris (Linnaeus, 1758) & 23 & $X$ & & & \\
\hline & & & Galeodea echinophora (Linnaeus, 1758) & 13 & $\mathrm{X}$ & & & \\
\hline & & & Hexaplex trunculus (Linnaeus, 1758) & 3 & $X$ & $\mathrm{X}$ & & \\
\hline Calliactis parasitica (Cough, 1842) & 45 & 59 & Ds $=8$ & & & & & \\
\hline \multirow[t]{8}{*}{ Dardanus calidus (Risso, 1827) } & & & Phalium granulatum (VonBorn, 1778) & 26 & & $\mathrm{X}$ & $\mathrm{X}$ & $\mathrm{X}$ \\
\hline & & & Hexaplex trunculus (Linnaeus, 1758) & 12 & $\mathrm{X}$ & $\mathrm{X}$ & $\mathrm{X}$ & \\
\hline & & & Tonna galea (Linnaeus, 1758) & 12 & & $\mathrm{X}$ & $\mathrm{X}$ & $X$ \\
\hline & & & $\begin{array}{l}\text { Charonia tritonis variegata (Lamarck, } \\
\text { 1816) }\end{array}$ & 3 & & & $X$ & $X$ \\
\hline & & & Galeodea echinophora (Linnaeus, 1758) & 2 & $\mathrm{X}$ & & & \\
\hline & & & Bolinus brandaris (Linnaeus, 1758) & 2 & $X$ & & & \\
\hline & & & Bolma rugosa (Linnaeus, 1767) & 1 & & & & $X$ \\
\hline & & & Aporrhais pespelecani (Linnaeus, 1758) & 1 & & & & $\mathrm{X}$ \\
\hline Calliactis parasitica (Cough, 1842) & 71.4 & 20 & Ds $=6$ & & & & & \\
\hline \multirow[t]{6}{*}{ Dardanus arrosor (Herbst, 1796) } & & & Phalium granulatum (VonBorn, 1778) & 13 & & $\mathrm{X}$ & $\mathrm{X}$ & \\
\hline & & & Galeodea echinophora (Linnaeus, 1758) & 2 & & & $\mathrm{X}$ & \\
\hline & & & Natica stercusmuscarum (Gmelin, 1791) & 2 & & & $\mathrm{X}$ & \\
\hline & & & Tonna galea (Linnaeus, 1758) & 1 & & & & $X$ \\
\hline & & & Hexaplex trunculus (Linnaeus, 1758) & 1 & $\mathrm{X}$ & & & \\
\hline & & & Bolinus brandaris (Linnaeus, 1758) & 1 & $\mathrm{X}$ & & & \\
\hline
\end{tabular}

$P \%$ percentage of hermit crabs with sea anemones to the number of individuals, $N$ number of hermit crab individuals in symbiosis with sea anemones, $D s$ diversity of shell utilization, $N s$ number of gastropod shell individuals (indicating the shell utilization by hermit crabs)

parasitica were the most dominant. The gastropod shells that were most frequently used by hermit crabs in symbiosis with sea anemones were Hexaplex trunculus (32\%), Bolinus brandaris (28\%), and Phalium granulatum (20\%). From these species, $B$. brandaris was exclusively recorded at Thermaikos, while $P$. granulatum was only found in the southern Aegean Sea.

The composition of the Hc/Sa symbiosis types showed an evident spatial pattern, following primarily the location of stations (Fig. 2a) and not the habitat type, with the exception of the muddy bottoms at Thermaikos Gulf. ANOSIM results showed non-significant differences in the distribution of the $\mathrm{Hc} / \mathrm{Sa}$ symbiosis types among habitats ( $R=0.43 P=0.09$ ). Similar results appeared considering also the diversity of shells utilized by each hermit crab (Fig. 2b, ANOSIM results $R=0.20 P=0.35$ ). While performing the same analyses using data only from seagrass meadows, a clear separation between the northern and the southern stations was noticed (Fig. 2c, d), which was significant according to ANOSIM results $(R=0.98$ $P<0.01$ and $R=1 P<0.01$, when considering also shell utilization diversity).

Dardanus calidus was the largest species with respect to its biomass, followed by D. arrosor, and Paguristes eremita the smallest. D. calidus crabs utilized shells of eight gastropod species. Small-sized individuals, constituting the bulk of the studied populations, occupied a variety of shells, whereas medium and large-sized ones were found only in the larger shells, i.e., Charonia tritonis variegata, Phalium granulatum, and Tonna galea (Fig. 3). Its congener, $D$. arrosor, showed a similar pattern (Fig. 3). Paguristes eremita, the population of which is constituted by medium and large size classes, utilized three shell species with the larger individuals mostly colonizing $H$. trunculus shells (Fig. 3). Finally, in the case of Pagurus excavatus, the almost equally represented size classes of its population occupied mainly $B$. brandaris shells (Fig. 3). 
Fig. 2 Non-metric multidimensional scaling ordination (nMDS) via BrayCurtis distances using relative abundance data of the Calliactis parasitica-hermit crab associations across sampling sites (a), considering also shell resource availability (b). Same analyses performed exclusively on data from seagrass meadows (c, d) habitat types samples
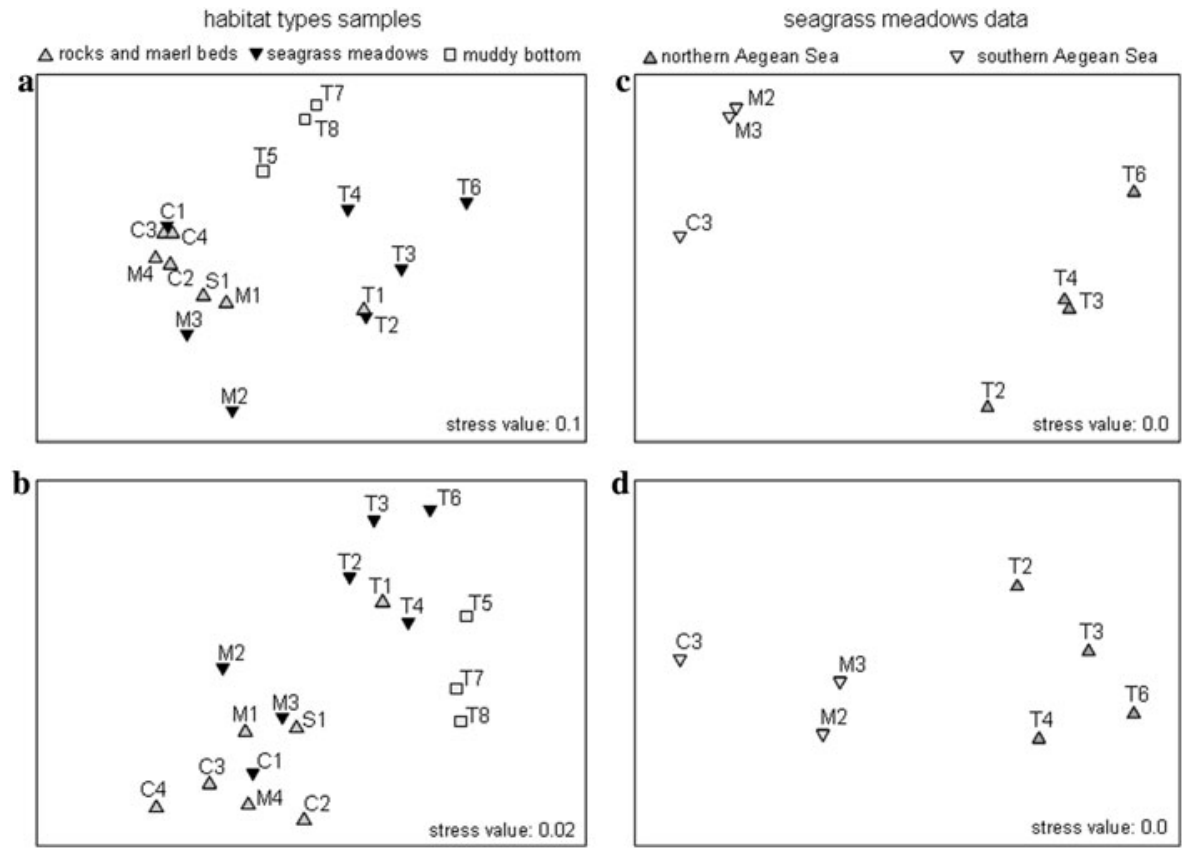

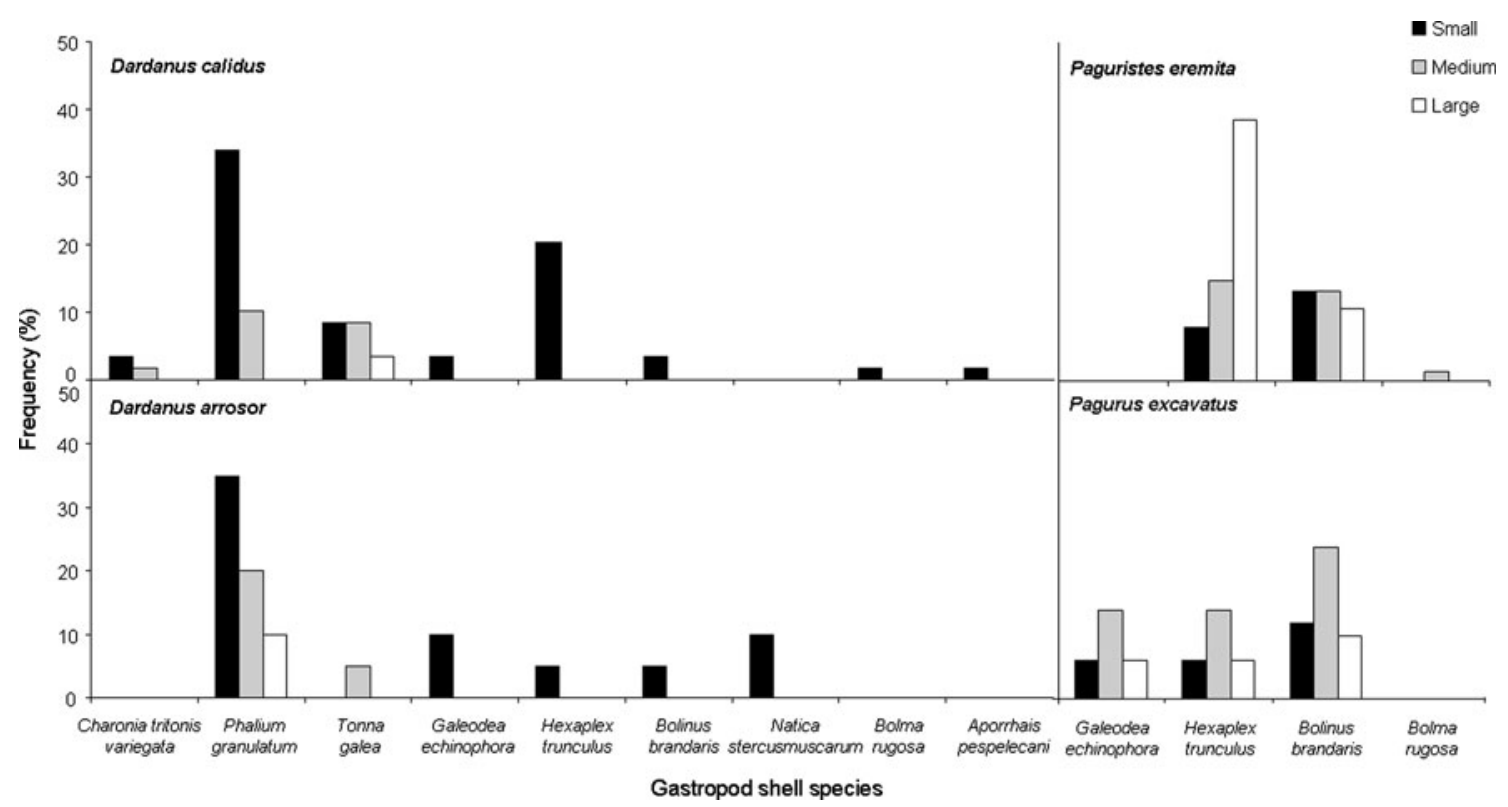

Fig. 3 Shell resource utilization patterns of Dardanus calidus, D. arrosor, Paguristes eremita, and Pagurus excavatus according to their size (estimated by using weight measurements). Small, medium, and large individuals' weight is up to 60,110 , and $170 \mathrm{~g}$,

MANOVA revealed significant differences in sea anemone utilization among hermit crab (Wilks' statistic $0.475 P<0.01$ ) and gastropod species (Wilks' statistic $0.609 P<0.01$ ) with large-sized species (i.e., Dardanus calidus, D. arrosor, Charonia tritonis variegata, Phalium respectively, for D. calidus; up to 40,80 , and $110 \mathrm{~g}$, respectively, for D. arrosor; up to 2,4 , and $7 \mathrm{~g}$, respectively, for $P$. eremita; and up to 5,11 , and $16 \mathrm{~g}$, respectively, for $P$. excavatus. Gastropod species are shown in decreasing shell size from left to right

granulatum, and Tonna galea) hosting more sea anemones, both in terms of abundance and biomass (Figs. 4, 5, respectively).

The examined biometric relationships were found significant for each $\mathrm{Hc} / \mathrm{Sa}$ symbiosis type $(P<0.01)$, the only 
Fig. 4 Sea anemone (Calliactis parasitica) utilization patterns according to hermit crab species. Bars represent standard deviation. All hermit crabs with sea anemones were pooled, regardless of sampling location and hermit crab size
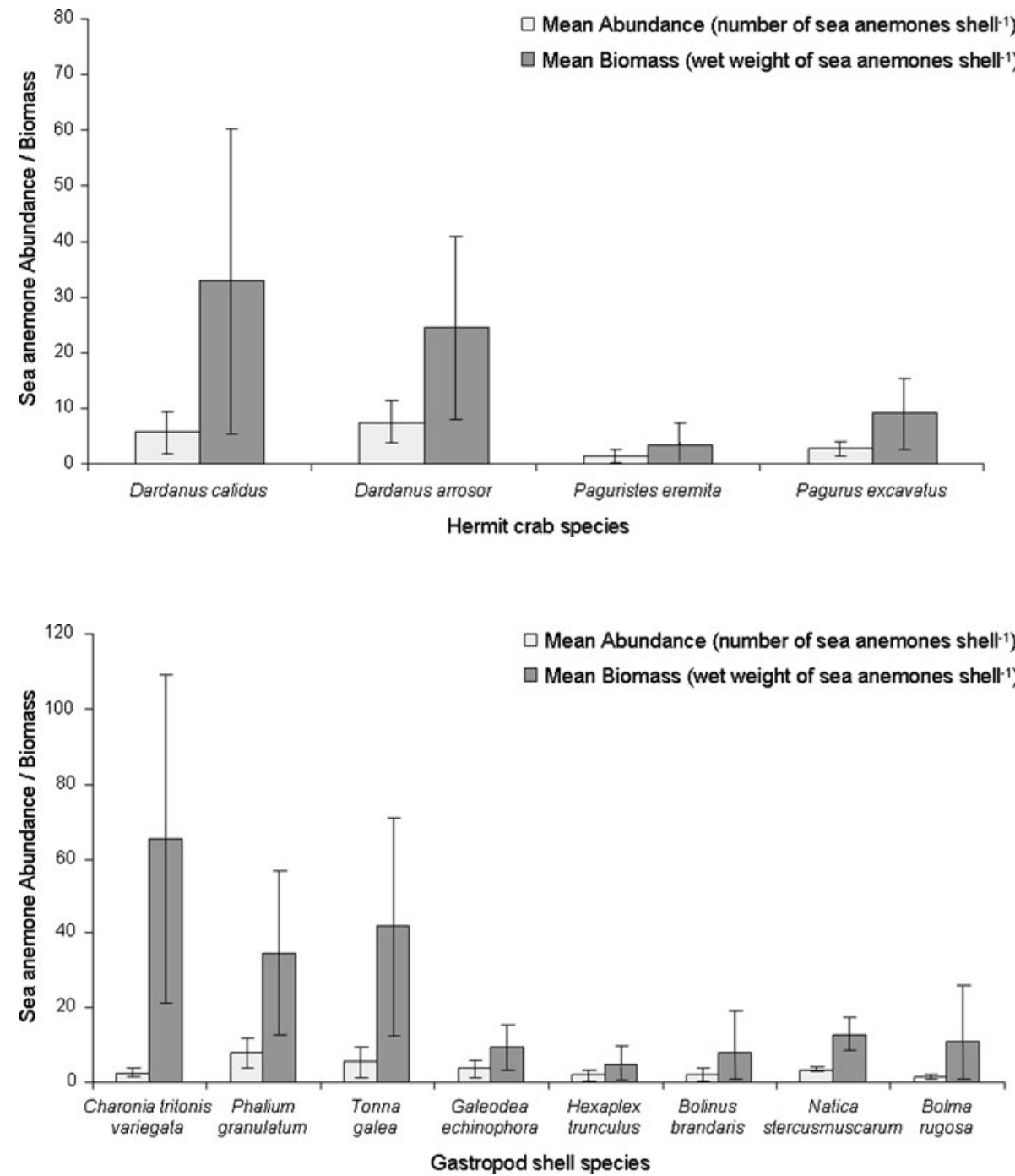

Fig. 5 Sea anemone (Calliactis parasitica) utilization patterns according to gastropod species. Bars represent standard deviation. All gastropods shells with sea anemones were pooled, regardless of sampling location and hermit crab species

Table 2 Biometric relationships for the hermit crab species that hosted sea anemones in the Aegean Sea

\begin{tabular}{|c|c|c|c|c|c|c|c|}
\hline Gastropod species & $N$ & $\begin{array}{l}\text { Allometric } \\
\text { relation Y/X }\end{array}$ & Allometric equation & $r$ & $R^{2}$ & $t$ value & Relationship ( $t$ test) \\
\hline \multirow[t]{2}{*}{ Pagurus excavatus } & 39 & $\mathrm{G} / \mathrm{H}$ & $\log Y=0.843+0.431 \log X$ & 0.707 & 0.500 & -6.855 & -Allometry \\
\hline & & $\mathrm{A} / \mathrm{H}$ & $\log Y=0.546+0.425 \log X$ & 0.310 & 0.096 & -2.376 & -Allometry \\
\hline \multirow[t]{2}{*}{ Dardanus arrosor } & 20 & $\mathrm{G} / \mathrm{H}$ & $\log Y=0.893+0.373 \log X$ & 0.629 & 0.396 & -5.269 & -Allometry \\
\hline & & $\mathrm{A} / \mathrm{H}$ & $\log Y=0.692+0.529 \log X$ & 0.323 & 0.105 & -3.161 & Not significant \\
\hline \multirow[t]{2}{*}{ Dardanus calidus } & 59 & $\mathrm{G} / \mathrm{H}$ & $\log Y=0.845+0.426 \log X$ & 0.635 & 0.403 & -8.319 & -Allometry \\
\hline & & $\mathrm{A} / \mathrm{H}$ & $\log Y=0.169+0.780 \log X$ & 0.655 & 0.429 & -1.818 & -Allometry \\
\hline \multirow[t]{2}{*}{ Paguristes eremita } & 75 & $\mathrm{G} / \mathrm{H}$ & $\log Y=0.606+0.995 \log X$ & 0.896 & 0.802 & 0.086 & Isometry \\
\hline & & $\mathrm{A} / \mathrm{H}$ & $\log Y=-0.272+1.144 \log X$ & 0.622 & 0.387 & 0.847 & Isometry \\
\hline
\end{tabular}

$G$ gastropod shell weight, $H$ hermit crabs weight, $A$ anemones weight, $N$ number of individuals, $r$ correlation coefficient, and $R^{2}$ determination coefficient

exception being the relationship between anemones and hermit crab biomass for the species Dardanus arrosor. Most examined relationships followed negative allometry (Table 2); thus, the relative increment of the hermit crab biomass was smaller than the relevant increment of its residence shell and/or the hosted anemones. The smallest species Paguristes eremita is an exception of the above pattern since the examined relationships were isometric (Table 2). 


\section{Discussion}

Hermit crab-Calliactis parasitica symbiosis types: spatial distribution

Sea anemones commonly colonize gastropod shells inhabited by hermit crabs. This case of mutualistic symbiosis, with a third species being involved (i.e., gastropods), has been described under the term "ecological triangle" (Ross and Sutton 1963) with reference to the coevolution of the participant species. Although the term has been accepted by other authors (Chintiroglou et al. 1992; Christidis et al. 1997), there is some doubt concerning its validity since the gastropods do not actively participate in the association, although their shells are vital for the development of the symbiosis.

The hermit crab-C. parasitica symbiosis types-were equally distributed among habitats, reflecting also the diversity of shell utilization. When analyzing data from seagrass meadows (the only habitat type sampled equally in the northern and southern Aegean Sea), a significant differentiation according to geographic sectors came up, probably linked with relevant environmental differences: the northern Aegean stations are mesotrophic, whereas the southern ones are oligotrophic (Gotsis-Skretas and Ignatiades 2005). Nevertheless, the small spatial scale of the present study does not allow any generalization of such a distribution pattern, and further larger-scale studies are required.

\section{Shell resource utilization}

Hermit crabs collected from the southern Aegean Sea, i.e., Dardanus species, inhabited a wider variety of shells than those in the north, i.e., Pagurus excavatus and Paguristes eremita. This probably reflects the different distribution of benthic gastropods in the Aegean Sea, where diversity increases toward the southern part (Koutsoubas et al. 1997). On the contrary, the population density of gastropods decreases due to the oligotrophic nature of the south Aegean (Gotsis-Skretas and Ignatiades 2005).

The various hermit crab species collected in the present study manifested different shell utilization according to their size, as has also been shown for other hermit crab species (Elwood and Neil 1992). Whether hermit crabs prefer a specific gastropod species remain unknown (see also Ates et al. 2007), and in most cases, the abundance of shells seems to be the major factor influencing shell utilization (Kellogg 1976; Barnes 1999). According to a literature review (see electronic supplement material), Dardanus arrosor inhabited 24 different gastropod shells, with Natica stercusmuscarum being a new record in the present study. Dardanus calidus has been previously reported to occupy shells of four species; this number increased to nine according to our results. Pagurus excavatus inhabits 17 different species, but in most cases, it was found in B. brandaris and G. echinophora shells, while Paguristes eremita most frequently occupied $H$. trunculus and $B$. brandaris shells, although it is occasionally found in the shells of other 33 gastropod species.

By examining the biometric relationships between hermit crab weight and its residence shell, smaller hermit crabs were assumed to inhabit heavier shells in proportion to their weight; similar results have been reported from analogous studies (Balasch and Cuadras 1976; Chintiroglou et al. 1992). The comparatively small crab species Paguristes eremita was an exception, as a proportional increment between its own size and its shell size was suggested. Besides reflecting simple mass relationships, these results may also be related to shell availability, in conformity with Hazlett (1995) who stated that hermit crabs modify their preference for shell size according to the availability. More specifically, when shell resources are limited, a trend toward gathering relatively oversized shells will assure hermit crabs growth and delay the need of changing the residence shell (Wada et al. 1997; Gherardi 2006), while under the opposite circumstances, hermit crabs may select better fitting shells.

\section{Calliactis parasitica utilization}

The hermit crab species Pagurus excavatus and Paguristes eremita have been previously reported in symbiosis with Calliactis parasitica in the Aegean Sea (Chintiroglou et al. 1992, Christidis et al. 1997), whereas Dardanus species are recorded for the first time in association with $C$. parasitica, in the eastern Mediterranean.

Sea anemone utilization patterns differed among hermit crab species and residence shells, with larger crabs and shells hosting an increased density and/or biomass of C. parasitica, at both intra- and inter-specific levels. Smaller hermit crabs carried a higher anemone biomass relative to their weight, as revealed by the relevant biometric relationships. However, Paguristes eremita and Dardanus arrosor were exceptions to the above pattern, as the former species carried very few anemones and the latter was densely covered. $P$. eremita has been collected from muddy substrata, and accordingly, it seems possible that this habitat type is a limiting factor suppressing the availability of $C$. parasitica. In the case of $D$. arrosor, which has been almost exclusively collected from Mykonos Island, a locally increased population of sea anemones, or the scarcity of suitable settlement surfaces, i.e., gastropod shells, may explain its dense cover by $C$. parasitica. Alternatively, increased predation levels toward $D$. arrosor in the area may explain this result, as it has been shown that 
hermit crabs have evolved a greater ability to gather sea anemones under such conditions (Ross and Boletzky 1979; Brooks and Mariscal 1986).

\section{Concluding remarks}

Summarizing, the following conclusions can be drown: (1) The symbiosis types of hermit crabs and sea anemones are distributed differently in the Aegean Sea; a pattern probably influenced by local environmental characteristics. (2) Shell utilization by hermit crab species is related with the size structure of hermit crab populations, although shell resource availability probably plays the most restrictive role. A selective behavior of hermit crabs toward the size of shells is suggested; nevertheless, selectivity to shells of certain gastropod species remains doubtful. (3) Sea anemone utilization pattern varies at both intra- and inter-specific levels with larger individuals hosting an increased abundance and/or biomass of anemones. Exceptions to the above scheme are related to local resource availability or other environmental factors.

Acknowledgments We are grateful to the captains and crews of the fishing vessels utilized in this study for their help during samplings. We are also grateful to Dr. Martin Thiel and two anonymous reviewers for their constructive criticism and commenting that highly improved our manuscript.

\section{References}

Ates AS, Katagan T, Kocatas A (2007) Gastropod shell species occupied by hermit crabs (Anomura: Decapoda) along the Turkish coast of the Aegean Sea. Turk J Zool 31:13-18

Balasch J, Cuadras J (1976) Role of association with Calliactis parasitica (Couch) in social behaviour of Dardanus arrosor (Herbst). Vie Milieu 26:281-291

Barnes DKA (1999) Ecology of tropical hermit crabs at Quirimba Island, Mozambique: shell characteristics and utilisation. Mar Ecol Prog Ser 183:241-251

Borjesson DL, Szelistowski WA (1989) Shell selection, utilization and predation in the hermit crab Clibanarius panamensis stimpson in a tropical mangrove estuary. J Exp Mar Biol Ecol 133:213-228

Brooks WR (1989) Hermit crabs alter sea anemone placement patterns for shell balance and reduced predation. J Exp Mar Biol Ecol 132:109-121

Brooks WR, Gwaltney CL (1993) Protection of symbiotic cnidarians by their hermit crab hosts: evidence for mutualism. Symbiosis 15:1-13

Brooks WR, Mariscal RN (1986) Population variation and behavioral changes in two pagurids in association with the sea anemone Calliactis tricolor (Lesueur). J Exp Mar Biol Ecol 103:275-289

Caruso T, Chemello R (2009) The size and shape of shells used by hermit crabs: a multivariate analysis of Clibanarius erythropus. Acta Oecologica 35:349-354

Chintiroglou Ch, Doumenc D, Koutsoubas D (1992) Allométrie d'une nouvelle association entre le Décapode Anomure Pagurus excavatus (Herbst, 1791) et l'Actinie Acontiaire Sagartiogeton undatus (Müller, 1788). Crustaceana 62:1-12

Christidis J, Chintiroglou Ch, Culley MB (1997) A study of the populations of Calliactis parasitica (Couch, 1842) in symbiosis with anomuran decapods in Thermaikos Gulf (N. Aegean Sea). Crustaceana 70:227-238

Clarke KR, Gorley NR (2006) PRIMER v6: user manual/tutorial. Primer-E, Plymouth

Conover MR (1978) The importance of various shell characteristics to the shell selection behavior of hermit crabs. J Exp Mar Biol Ecol 32:131-142

Elwood RW, Neil SJ (1992) Assessments and decisions: a study of information gathering by hermit crabs. Chapman and Hall, London

Gherardi F (2006) Fighting behavior in hermit crabs: the combined effect of resource-holding potential and resource value in Pagurus longicarpus. Behav Ecol Sociobiol 59:500-510

Gotsis-Skretas O, Ignatiades L (2005) Phytoplankton in pelagic and coastal waters. In: Papathanassiou E, Zenetos A (eds) State of the hellenic marine environment. HCMR, Athens, pp 187-193

Gusmão LC, Daly M (2010) Evolution of sea anemones (Cnidaria: Actiniaria: Hormathiidae) symbiotic with hermit crabs. Mol Phyl Evol 56:868-877

Hahn DR (1998) Hermit crab shell use patterns: response to previous shell experience and to water flow. J Exp Mar Biol Ecol 228:35-51

Hazlett BA (1981) The behavioral ecology of hermit crabs. Annu Rev Ecol Syst 12:1-22

Hazlett BA (1995) Behavioural plasticity in Crustacea: why not more? J Exp Mar Biol Ecol 193:57-66

Henry SM (1966) Symbiosis. I Associations of microorganisms, plants and marine organisms. Academic Press, New York

Imafuku M, Yamamoto T, Ohta M (2000) Predation on symbiont sea anemones by their host hermit crab Dardanus pedunculatus. Mar Freshw Behav Phy 33:221-232

Kellogg CW (1976) Gastropod Shells: a potentially limiting resource for hermit crabs. J Exp Mar Biol Ecol 22:101-111

Koutsoubas D, Koukouras A, Voultsiadou-Koukoura E (1997) Prosobranch mollusc fauna of the Aegean Sea: new information, checklist, distribution. Israel J Zool 43:19-54

Patzner RA (2004) Associations with sea anemones in the Mediterranean Sea: a review. Ophelia 58:1-11

Reese ES (1963) The behavioural mechanisms underlying shell selection by hermit crabs. Behaviour 21:78-126

Ross DM (1979) "Stealing" of the symbiotic anemone, Calliactis parasitica, in interspecific and intraspecific encounters of three species of Mediterranean pagurids. Can J Zool 57:1181-1189

Ross DM, Boletzky S (1979) The association between the pagurid Dardanus arrosor and the actinian Calliactis parasitica. Recovery of activity in "inactive" $D$. arrosor in the presence of cephalopods. Mar Behav Physiol 6:175-184

Ross DM, Sutton L (1963) A sea anemone, a hermit crab and a shell. An ecological triangle. Proc Int Congr Zool 1:62

Sokal R, Rohlf FJ (1987) Introduction to Biostatistics. Freeman and Company, New York

Stachowitsch M (1980) The epibiotic and endolithic species associated with the gastropod shells inhabited by the hermit crabs Paguristes oculatus and Pagurus cuanensis. Mar Ecol 1:73-101

Wada S, Ohmori H, Goshima S, Nakao S (1997) Shell-size preference of hermit crabs depends on their growth rate. Anim Behav $54: 1-8$

Williams JD, McDermott JJ (2004) Hermit crab biocoenoses: a worldwide review of the diversity and natural history of hermit crab associates. J Exp Mar Biol Ecol 305:1-128 